\title{
Fish consumption and omega-3-fatty acids in prevention of diet-related noncommunicable diseases
}

\author{
Jubbin Jagan Jacob \\ Department of Medicine, Endocrine and Diabetes Unit, Christian Medical College and Hospital, Ludhiana, Punjab, India
}

\section{A B S T R A C T}

Diet-related noncommunicable diseases (DR-NCDs) which include obesity, hypertension, lipid disorders, type 2 diabetes mellitus, and cardiovascular (CV) disease are more common among people of South Asian descent because of genetic and other poorly understood factors. Indians are also one of the lowest consumers of fish and shellfish in the world despite being blessed with an extensive coastline. Consumption of fatty fish and fish oils supplementation has been demonstrated to improve blood pressure, lipid profiles, and CV outcomes. Data are still unclear if there is any impact on glucose intolerance with increased consumption of fatty fish or use of fish oils and omega-3-fatty acid (O3FA) supplements. The review focuses on the mechanisms of improvements with O3FAs on various aspects of DR-NCDs and reviews of current clinical data.

Key words: Cardiovascular disease, fatty fish, fish oils, noncommunicable diseases, omega-3-fatty acids

\section{INTRODUCTION}

Diet-related noncommunicable diseases (DR-NCDs) include obesity, hyperlipidemia, glucose intolerant states including type 2 diabetes mellitus (T2DM), hypertension, and cardiovascular (CV) disease. DR-NCDs are more common among people of South Asian descent than many other racial groups. The reasons are likely to compose of genetics and additional poorly understood factors. ${ }^{11}$ Currently, India has one of the largest numbers of patients with glucose intolerance and diabetes mellitus. A 10-year-old report from the World Health Organization in 2006 suggested that India was losing USD 9 billion worth of national income every year because of premature mortality and morbidity. ${ }^{[2]}$

\begin{tabular}{|c|l|}
\hline \multicolumn{2}{|c|}{ Access this article online } \\
\hline Quick Response Code: & Website: \\
\hline & www.joshd.net \\
\hline & \\
\hline & \\
\hline
\end{tabular}

It is assumed that the lower rates of CV disease and DR-NCDs among the Eskimos in Greenland and among the Japanese might be related to their higher per capita fish consumption. On an average, an Eskimo consumes over $400 \mathrm{~g}$ of fish a day while the average Japanese consumes about $100 \mathrm{~g}$ of fish a day. ${ }^{[3]}$ This is in stark contrast to a per capita consumption of $3 \mathrm{~kg}$ of fish among an average Indian in a whole year as per data published in 2012. Consumption is much higher in coastal states (average $12 \mathrm{~kg}$ /year) and much lower in the noncoastal areas $(2 \mathrm{~kg} /$ year). Even among the coastal states, cultural and religious factors play a role in consumption of fish with states such as Gujarat continuing to be low fish consuming despite being a major producer of marine fish. ${ }^{[4]}$

\begin{abstract}
This is an open access article distributed under the terms of the Creative Commons Attribution-NonCommercial-ShareAlike 3.0 License, which allows others to remix, tweak, and build upon the work non-commercially, as long as the author is credited and the new creations are licensed under the identical terms.
\end{abstract}

For reprints contact: reprints@medknow.com

How to cite this article: Jacob JJ. Fish consumption and omega-3-fatty acids in prevention of diet-related noncommunicable diseases. J Soc Health Diabetes 2016;4:115-20.

Corresponding Author: Prof. Jubbin Jagan Jacob, Department of Medicine, Endocrine and Diabetes Unit, Christian Medical College and Hospital, Ludhiana - 141 008, Punjab, India. E-mail: jubbin.jacob@gmail.com 
Research in this field however has given inconsistent results over the years. Nevertheless, epidemiological, observational, and clinical trials have demonstrated myriad benefits of fish intake and in particular intake of fish oils in the primary and secondary prevention of CV disease. ${ }^{[5,6]}$ This review attempts to summarize the current knowledge of the role of fish oils and other omega-3-fatty acids (O3FAs) in the primary and secondary prevention of CV disease and other DR-NCDs.

\section{OMEGA-3 FATTY ACIDS BIOCHEMISTRY}

O3FAs are biological active compounds primarily derived from fish (eicosapentaenoic acid [EPA] and docosahexaenoic acid [DHA]). ${ }^{[7]}$ Plant sources of O3FAs include the alpha-linolenic acid (ALA) containing flaxseeds, walnuts, canola oil, and chia seeds. ${ }^{[8]}$ ALA can be converted to EPA and DHA in the human body by elongation and desaturation. Among fish, the oily fishes (tuna, mackerel, cod, herring, sardines, and salmon) are rich sources of O3FA. ${ }^{[9]}$

O3FAs belong to a class of essential long-chain highly unsaturated fatty acids consisting in addition to O3FA to O6FA. The classification of these fatty acids is given in Figure 1. All three of these fatty acids cannot be de novo synthesized in the human body and are hence termed essential fatty acids. ${ }^{[10]}$

\section{PROPOSED MECHANISMS BY WHICH OMEGA-3-FATTY ACIDS/FISH OILS IMPROVE NONCOMMUNICABLE DISEASE OUTCOMES}

Experimental studies of O3FA on prevention and amelioration of NCDs have continuously expanded without sufficient clarity about the final mechanisms by

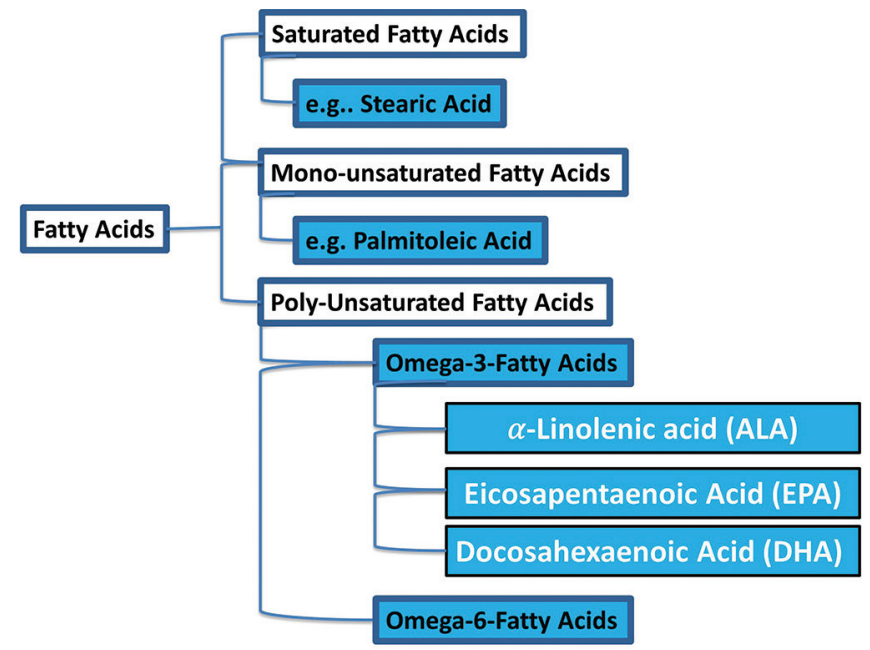

Figure 1: Classification of fatty acids which they benefit. They most likely benefit via alteration of eicosanoid profiles, regulating gene expression, modulating membrane functions on cells and cell organelles, and changes in tissue metabolism. ${ }^{[1]}$ These compounds have been clearly demonstrated to lead to changes in lipid profile, inflammatory milieu, lowering blood pressure, stabilizing atherosclerotic plaques, and improvement in glucose tolerance. ${ }^{[12]}$

\section{Blood pressure effects}

Studies have indicated a modest decrease in systolic and diastolic blood pressures, with supplementation of O3FA. Mechanisms for blood pressure lowering might include augmentation of vagal tone which leads to improved autonomic functions, changes in cardiac electrophysiology, and improvements in the diastolic filling of the cardiac ventricles. ${ }^{[13]}$ The effect on the vagal tone is likely to be of most importance as studies have suggested that fish consumption of 3 or more times a week was associated with reduction in heart rate by $3 \mathrm{bpm} .{ }^{[14]}$

Another potential mechanism of blood pressure lowering could relate to the antagonism of the vasoconstrictive effects of arachidonic acid-derived prostaglandins and thromboxanes. Prostaglandins derived from EPA/DHA such as lipoxins and resolvins antagonize the vasoconstricting prostaglandins and improve vascular tone. O3FAs appear to suppress the activity of angiotensin converting enzyme and lead to decreased production of angiotension-2. O3FAs also improve the vasodilatory effects of endothelial nitric oxide. ${ }^{[15,16]}$

\section{Anti-inflammatory effects}

Eicosanoids are arachidonic acid derivatives which promote inflammation and are derived from O6FAs. O3FAs intake reduces the production of eicosanoids and reduces inflammation and oxidative stress. The effect is only obvious with reasonably good intake of EPA/DHA of around $2 \mathrm{~g}$ a day. ${ }^{[17]}$

The primary prostaglandins derived from EPA and DHA are called resolvins (resolution phase interaction proteins). The resolvins possess potent anti-inflammatory action and exert direct immunomodulatory effects on neutrophils, dendritic cells, and macrophages. ${ }^{[18]}$ These anti-inflammatory effects appear to have cardioprotective benefits though they do not appear to benefits disease with more significant inflammations such as arthritis and inflammatory bowel diseases. ${ }^{[18,19]}$

\section{Lipid effects}

The consistent effects of O3FAs to reduce plasma triglycerides (TG) without increasing the low-density 
lipoprotein cholesterol have been evident from epidemiological and clinical studies. ${ }^{[20]}$ Fish oils reduce hepatic TG production via inhibition of hepatic enzyme synthesis responsible for TG synthesis and enhance the clearance of the circulation plasma TGs. A decrease in lipogenesis also decreases the availability of fatty acids for TG production. ${ }^{[20-22]}$ Substantial reduction in TGs is seen when O3FAs are used in doses of 3-4 g/day. ${ }^{[23]}$

\section{Effect on glucose intolerance}

Fish oils in modest doses do not appear to have any effect on insulin secretion (beta cell function) and insulin sensitivity in normal individuals. ${ }^{[24]}$ In a prospective Chinese population-based cohort, an inverse relation was noted between intake of fish, shellfish, and long-chain fatty acids and T2DM in women. ${ }^{[25]}$ These marine-based O3FAs were not associated with any increase in the risk of diabetes. A study involving middle aged woman who were prospectively followed up for 16 years suggested that intake of long chain fatty acids was associated with an increased risk of T2DM. ${ }^{[26]}$ A Dutch study of adults above 55 years with no preexisting glucose intolerance also showed a positive relation between total fish intake and the risk of new-onset type 2 diabetes. EPA, DHA, and fatty fish intake was however not associated with the risk of diabetes, but the consumption of lean fish was thought to be a causative factor. ${ }^{[27]}$

Subsequent studies including a meta-analysis suggested that considerable study and statistical heterogeneity with significant geographical variations that make an accurate assessment of risk of diabetes with fish and fish oil intake difficult to interpret. ${ }^{[28]}$ However it has been observed that South Asians appear to have a reduced risk of T2DM with consumption of fish and fish oils. ${ }^{[29]}$

\section{Effect on atherosclerosis}

In addition to the indirect effects of O3FA and fish oils on atherogenesis mediated by the promotion of a pro-inflammatory milieu with antagonism of the anti-inflammatory O6FA-derived prostaglandins, ${ }^{[30]}$ improvement in vascular tone by increasing nitrous oxide-mediated vasodilation and effects on the lipids and fish oils have direct effects on the processes that underlie atherogenesis. ${ }^{[16]}$

Primary among them is vascular smooth muscle proliferation, a decrease in plaque formation and stabilization of the fibrous cap of an atherosclerotic plaque prone to rupture. ${ }^{[31,32]}$

\section{Effect on biological aging and neurodegeneration}

Recent research has suggested that fish oil consumption slows down biological aging by preserving telomere length.
A study carried in over 600 patients with stable heart disease showed that baseline O3FA levels in the plasma were found to be inversely proportional to the telomere shortening during 5 years of follow-up. Shortening of telomeres has previously been associated with poorer prognosis in patients with heart disease. ${ }^{[33]}$

Together with O6FAs, O3FAs constitute over 30-35\% of total brain fatty acids. There is a suggestion that diets containing fish and fish oils may benefit cognition. Human studies however are not conclusive. A recent meta-analysis suggested that patients with dementia have lower blood levels of EPA and DHA. ${ }^{[34]}$

\section{CLINICAL STUdies WITH OMEgA-3-FATty ACIDS}

Although individual studies suggested benefits of O3FA supplementation in the secondary prevention of CV events, recent systemic reviews and meta-analysis have not shown clear-cut benefits. Large trials of fish oil supplementation have yielded contradictory results.

The studies that favor O3FA in secondary prevention came with the following conclusions.

1. Geleijnse et al. ${ }^{[35]}$ - higher intake (>0.5 g/day) of O3FA in older hypertensive patients independently reduces blood pressure

2. Burr et al. ${ }^{[36]}$ - fatty fish intake causes $29 \%$ reduction in mortality after a recent myocardial infarction (MI) in men

3. Campos et al. ${ }^{[37]}$ - consumption of plant-derived ALA reduces risk of recurrent $\mathrm{MI}$ in patients with previous $\mathrm{MI}$

4. Yokoyama et al. ${ }^{[38]}$ - EPA supplementation caused a $19 \%$ reduction in major CV events in patients with hypercholesterolemia

5. Bairati et al. ${ }^{[39]}$ - patients on O3FA supplements undergoing primary angioplasty had less chances of restenosis

6. Calò et al. ${ }^{[40]}$ - preoperative administration of O3FA in patients undergoing coronary artery bypass graft $(\mathrm{CABG})$ improved postoperative outcomes including reduced risk of arrhythmias and reduced hospital stay

7. GISSi-HF study ${ }^{[41]}$ - O3FA supplementation in patients with heart failure reduces mortality and hospitalization for heart failure.

On the other hand, studies that contradict the benefits of O3FA in ischemic heart disease came with these following conclusions.

1. Burr et al. ${ }^{[42]}$ - two portions of oily fish/3 fish oil capsules daily caused a higher risk of cardiac death in men over the age of 70 years 
2. Kromhout et al. ${ }^{[43]}$ - low-dose EPA-DHA/ALA did not reduce $\mathrm{CV}$ events in patients with recent MI

3. Rauch et al. ${ }^{[4]}$ - no significant decrease in arrhythmias or sudden cardiac death in patients with recent MI

4. Reis et al..$^{[45]}$ - the incidence of restenosis was found to be higher in the group that was supplemented with fish oils

5. Saravanan et al..$^{[46]}$ - polyunsaturated fatty acids administration before CABG did not change postoperative outcomes

6. Dijkstra et al. ${ }^{[47]}$ - fish oils did not change outcomes in patients with heart failure

7. Belin et al. ${ }^{[48]}$ - no association with EPA/DHA intake with outcomes in patients with heart failure.

Some of the reasons for these discordant results could be:

1. Patients from populations with high baseline fatty fish intake and high baseline O3FA levels do not seem to derive any additional benefit with supplementation

2. Many trials on secondary prevention were not long enough to make meaningful contributions

3. Patient included in recent trails with O3FA would receive far more aggressive optimal therapy with higher doses of statins and other cardioprotective medications that larger sample size with longer follow-up would be required for O3FA supplementation to show additional benefits.

\section{PHARMACOLOGICAL PREPARATIONS, DOSING, AND ADVERSE EFFECTS}

For primary prevention of heart disease, the American Heart Association (AHA) recommends EPA and DHA intake of $0.5 \mathrm{~g} /$ day. This can be substituted for two or more servings of $3.5 \mathrm{oz}$ servings of fatty fish at least twice a week. This appears to be a useful guide for the prevention of DR-NCDS as well. ${ }^{[49]}$ The risk of glucose intolerance at this dosing is minimal. The American Diabetes Association has not recommended supplementation of O3FA in patients with diabetes but recommend that patients consume $2-3$ oz servings of fish in a week. ${ }^{[50]}$

For secondary prevention in patients with established $\mathrm{CV}$ disease, the AHA recommends at least $1 \mathrm{~g} /$ day of EPA and DHA preferably sourced from seafood sources. In patients with hypertriglyceridemia, the recommended dosing is $2-4 \mathrm{~g}$ a day. ${ }^{[49]}$

Fatty fish in polluted environments may contain traces of mercury. Pregnant woman is probably better advised to avoid fatty fish and consume $0.3 \mathrm{~g}$ of pharmacological supplement of fish oil. ${ }^{[51]}$
Despite a large number of organizations with recommendations for fish oil intake, there still is no dietary reference intake (DRI) established for fish oils. A comprehensive DRI consisting of estimated average requirements, recommended daily allowance, adequate intake, and tolerable upper intake levels needs to be still established for this vital nutrient. ${ }^{[51]}$

The only adverse event noted in trials with higher doses (>4 g/day) was nausea. Patients occasionally complain of a fishy taste, especially with belching. Sourcing EPA/DHA from large fatty fish could in theory increase risk of mercury overdosing. This is more of concern in young children, pregnant, and lactating women.

\section{CONCLUSION}

Fish consumption in our country is considerably lower than in other parts of the world despite our vast coastline and abundant marine resources. Even in coastal parts of our country, there has been a decline in the total consumption of fish in the last two decades. Fatty fish consumption, fish oils, and supplementation of O3FAs may be one of the ways for improving the DR-NCD profile of our country. Despite the risk of possible adverse effects on glucose intolerance, the benefits on lipids, blood pressure, and atherosclerotic disease far outweigh the risks.

Financial support and sponsorship

Nil.

\section{Conflicts of interest}

There are no conflicts of interest.

\section{REFERENCES}

1. Misra A, Khurana L. Obesity and the metabolic syndrome in developing countries. J Clin Endocrinol Metab 2008;93 11 Suppl 1:S9-30.

2. Abegunde D, Stanciole A. World Health Organization Working Paper: An Estimation of the Economic Impact of Chronic Non-Communicable Diseases in Selected Countries; 2006. p. 1-21. Available from: http://www.who.int/chp/working_paper_ growth\%20model29may.pdf. [Last accessed on 2016 Jun 20].

3. Kromhout D, Bosschieter EB, de Lezenne Coulander C. The inverse relation between fish consumption and 20-year mortality from coronary heart disease. N Engl J Med 1985;312:1205-9.

4. Ravikanth L, Kavikumar KS. Caught in the 'Net': Fish Consumption Patterns of Coastal Regions in India. 2015, Madras School of Economics. Available from: http://www.mse.ac.in/pub/ Working\%20Paper\%20110.pdf. [Last accessed on 2016 Jun 21].

5. Kris-Etherton PM, Harris WS, Appel LJ; American Heart Association. Nutrition Committee. Fish consumption, fish oil, omega-3 fatty acids, and cardiovascular disease. Circulation 2002;106:2747-57.

6. American Heart Association Nutrition Committee, Lichtenstein AH, 
Appel LJ, Brands M, Carnethon M, Daniels S, et al. Diet and lifestyle recommendations revision 2006: A scientific statement from the American Heart Association Nutrition Committee. Circulation 2006;114:82-96.

7. Pan A, Chen M, Chowdhury R, Wu JH, Sun Q, Campos H, et al. Alpha-linolenic acid and risk of cardiovascular disease: A systematic review and meta-analysis. Am J Clin Nutr 2012;96:1262-73.

8. Welch AA, Shakya-Shrestha S, Lentjes MA, Wareham NJ, Khaw KT. Dietary intake and status of n-3 polyunsaturated fatty acids in a population of fish-eating and non-fish-eating meat-eaters, vegetarians, and vegans and the product-precursor ratio [corrected] of alpha-linolenic acid to long-chain n-3 polyunsaturated fatty acids: Results from the EPIC-Norfolk cohort. Am J Clin Nutr 2010;92:1040-51.

9. Harris WS. Fish oil supplementation: Evidence for health benefits. Cleve Clin J Med 2004;71:208-10.

10. Hussein N, Ah-Sing E, Wilkinson P, Leach C, Griffin BA, Millward DJ. Long-chain conversion of [13C] linoleic acid and alpha-linolenic acid in response to marked changes in their dietary intake in men. J Lipid Res 2005;46:269-80.

11. Mozaffarian D, Wu JH. Omega-3 fatty acids and cardiovascular disease: Effects on risk factors, molecular pathways, and clinical events. J Am Coll Cardiol 2011;58:2047-67.

12. Delgado-Lista J, Perez-Martinez P, Lopez-MirandaJ, Perez-JimenezF. Long chain omega-3 fatty acids and cardiovascular disease: A systematic review. Br J Nutr 2012;107 Suppl 2:S201-13.

13. Morris MC, Sacks F, Rosner B. Does fish oil lower blood pressure? A meta-analysis of controlled trials. Circulation 1993;88:523-33.

14. Mozaffarian D, Gottdiener JS, Siscovick DS. Intake of tuna or other broiled or baked fish versus fried fish and cardiac structure, function, and hemodynamics. Am J Cardiol 2006;97:216-22.

15. Fischer R, Dechend R, Qadri F, Markovic M, Feldt S, Herse F, et al. Dietary $\mathrm{n}-3$ polyunsaturated fatty acids and direct renin inhibition improve electrical remodeling in a model of high human renin hypertension. Hypertension 2008;51:540-6.

16. Harris WS, Rambjør GS, Windsor SL, Diederich D. N-3 fatty acids and urinary excretion of nitric oxide metabolites in humans. Am J Clin Nutr 1997;65:459-64.

17. Rees D, Miles EA, Banerjee T, Wells SJ, Roynette CE, Wahle KW, et al. Dose-related effects of eicosapentaenoic acid on innate immune function in healthy humans: A comparison of young and older men. Am J Clin Nutr 2006;83:331-42.

18. Serhan CN, Clish CB, Brannon J, Colgan SP, Chiang N, Gronert K. Novel functional sets of lipid-derived mediators with antiinflammatory actions generated from omega-3 fatty acids via cyclooxygenase 2-nonsteroidal antiinflammatory drugs and transcellular processing. J Exp Med 2000;192:1197-204.

19. Serhan CN, Clish CB, Brannon J, Colgan SP, Gronert K, Chiang N. Anti-microinflammatory lipid signals generated from dietary $n-3$ fatty acids via cyclooxygenase- 2 and transcellular processing: $A$ novel mechanism for NSAID and n-3 PUFA therapeutic actions. J Physiol Pharmacol 2000;51 (4 Pt 1):643-54.

20. Harris WS, Miller M, Tighe AP, Davidson MH, Schaefer EJ. Omega-3 fatty acids and coronary heart disease risk: Clinical and mechanistic perspectives. Atherosclerosis 2008;197:12-24.

21. Harris WS, Bulchandani D. Why do omega-3 fatty acids lower serum triglycerides? Curr Opin Lipidol 2006;17:387-93.

22. Faeh D, Minehira K, Schwarz JM, Periasamy R, Park S, Tappy L. Effect of fructose overfeeding and fish oil administration on hepatic de novo lipogenesis and insulin sensitivity in healthy men. Diabetes 2005;54:1907-13.

23. Samuel S, Peskin B, Arondekar B, Alperin P, Johnson S, Blumenfeld $\mathrm{I}$, et al. Estimating health and economic benefits from using prescription omega-3 fatty acids in patients with severe hypertriglyceridemia. Am J Cardiol 2011;108:691-7.

24. Giacco R, Cuomo V, Vessby B, Uusitupa M, Hermansen K, Meyer BJ, et al. Fish oil, insulin sensitivity, insulin secretion and glucose tolerance in healthy people: Is there any effect of fish oil supplementation in relation to the type of background diet and habitual dietary intake of n-6 and n-3 fatty acids? Nutr Metab Cardiovasc Dis 2007;17:572-80.

25. Villegas R, Xiang YB, Elasy T, Li HL, Yang G, Cai H, et al. Fish, shellfish, and long-chain n-3 fatty acid consumption and risk of incident type 2 diabetes in middle-aged Chinese men and women. Am J Clin Nutr 2011;94:543-51.

26. Djoussé L, Gaziano JM, Buring JE, Lee IM. Dietary omega-3 fatty acids and fish consumption and risk of type 2 diabetes. Am J Clin Nutr 2011;93:143-50.

27. van Woudenbergh GJ, van Ballegooijen AJ, Kuijsten A, Sijbrands EJ, van Rooij FJ, Geleijnse JM, et al. Eating fish and risk of type 2 diabetes: A population-based, prospective follow-up study. Diabetes Care 2009;32:2021-6.

28. Wallin A, Di Giuseppe D, Orsini N, Patel PS, Forouhi NG, Wolk A. Fish consumption, dietary long-chain n-3 fatty acids, and risk of type 2 diabetes: Systematic review and meta-analysis of prospective studies. Diabetes Care 2012;35:918-29.

29. Zheng JS, Huang T, Yang J, Fu YQ, Li D. Marine n-3 polyunsaturated fatty acids are inversely associated with risk of type 2 diabetes in Asians: A systematic review and meta-analysis. PLoS One 2012;7:e44525.

30. Bouwens M, van de Rest O, Dellschaft N, Bromhaar MG, de Groot LC, Geleijnse JM, et al. Fish-oil supplementation induces antiinflammatory gene expression profiles in human blood mononuclear cells. Am J Clin Nutr 2009;90:415-24.

31. Calder PC. The role of marine omega-3 (n-3) fatty acids in inflammatory processes, atherosclerosis and plaque stability. Mol Nutr Food Res 2012;56:1073-80.

32. Shahzad K, Chokshi A, Schulze PC. Supplementation of glutamine and omega-3 polyunsaturated fatty acids as a novel therapeutic intervention targeting metabolic dysfunction and exercise intolerance in patients with heart failure. Curr Clin Pharmacol 2011;6:288-94.

33. Farzaneh-Far R, Lin J, Epel ES, Harris WS, Blackburn EH, Whooley MA. Association of marine omega-3 fatty acid levels with telomeric aging in patients with coronary heart disease. JAMA 2010;303:250-7.

34. Lin PY, Chiu CC, Huang SY, Su KP. A meta-analytic review of polyunsaturated fatty acid compositions in dementia. J Clin Psychiatry 2012;73:1245-54.

35. Geleijnse JM, Giltay EJ, Grobbee DE, Donders AR, Kok FJ. Blood pressure response to fish oil supplementation: Metaregression analysis of randomized trials. J Hypertens 2002;20:1493-9.

36. Burr ML, Fehily AM, Gilbert JF, Rogers S, Holliday RM, Sweetnam PM, et al. Effects of changes in fat, fish, and fibre intakes on death and myocardial reinfarction: Diet and reinfarction trial (DART). Lancet 1989;2:757-61.

37. Campos H, Baylin A, Willett WC. Alpha-linolenic acid and risk of nonfatal acute myocardial infarction. Circulation 2008;118:339-45.

38. Yokoyama M, Origasa $H$, Matsuzaki M, Matsuzawa $Y$, Saito $Y$, Ishikawa $Y$, et al. Effects of eicosapentaenoic acid on major coronary events in hypercholesterolaemic patients (JELIS): A randomised open-label, blinded endpoint analysis. Lancet 2007;369:1090-8.

39. Bairati I, Roy L, Meyer F. Double-blind, randomized, controlled trial of fish oil supplements in prevention of recurrence of stenosis after coronary angioplasty. Circulation 1992;85:950-6.

40. Calò L, Bianconi L, Colivicchi F, Lamberti F, Loricchio ML, 
de Ruvo E, et al. N-3 Fatty acids for the prevention of atrial fibrillation after coronary artery bypass surgery: A randomized, controlled trial. J Am Coll Cardiol 2005;45:1723-8.

41. Tavazzi L, Maggioni AP, Marchioli R, Barlera S, Franzosi MG, Latini $R$, et al. Effect of $n-3$ polyunsaturated fatty acids in patients with chronic heart failure (the GISSI-HF trial): A randomised, double-blind, placebo-controlled trial. Lancet 2008;372:1223-30.

42. Burr ML, Ashfield-Watt PA, Dunstan FD, Fehily AM, Breay P, Ashton T, et al. Lack of benefit of dietary advice to men with angina: Results of a controlled trial. Eur J Clin Nutr 2003;57:193-200.

43. Kromhout D, Giltay EJ, Geleijnse JM; Alpha Omega Trial Group. $\mathrm{N}-3$ fatty acids and cardiovascular events after myocardial infarction. N Engl J Med 2010;363:2015-26.

44. Rauch B, Schiele R, Schneider S, Diller F, Victor N, Gohlke H, et al. Omega, a randomized, placebo-controlled trial to test the effect of highly purified omega-3 fatty acids on top of modern guideline-adjusted therapy after myocardial infarction. Circulation 2010;122:2152-9.

45. Reis GJ, Boucher TM, Sipperly ME, Silverman DI, McCabe CH, Baim DS, et al. Randomised trial of fish oil for prevention of restenosis after coronary angioplasty. Lancet 1989;2:177-81.
46. Saravanan P, Bridgewater B, West AL, O'Neill SC, Calder PC, Davidson NC, et al. Omega-3 fatty acid supplementation does not reduce risk of atrial fibrillation after coronary artery bypass surgery: A randomized, double-blind, placebo-controlled clinical trial. Circ Arrhythm Electrophysiol 2010;3:46-53.

47. Dijkstra SC, Brouwer IA, van Rooij FJ, Hofman A, Witteman JC, Geleijnse JM. Intake of very long chain n-3 fatty acids from fish and the incidence of heart failure: The Rotterdam Study. Eur J Heart Fail 2009;11:922-8.

48. Belin RJ, Greenland P, Martin L, Oberman A, Tinker L, Robinson J, et al. Fish intake and the risk of incident heart failure: The Women's Health Initiative. Circ Heart Fail 2011;4:404-13.

49. Harris WS, Kris-Etherton PM, Harris KA. Intakes of long-chain omega-3 fatty acid associated with reduced risk for death from coronary heart disease in healthy adults. Curr Atheroscler Rep 2008;10:503-9.

50. Fares H, Lavie CJ, DiNicolantonio JJ, O'Keefe JH, Milani RV. Omega-3 fatty acids: A growing ocean of choices. Curr Atheroscler Rep 2014;16:389.

51. Flock MR, Harris WS, Kris-Etherton PM. Long-chain omega-3 fatty acids: Time to establish a dietary reference intake. Nutr Rev 2013;71:692-707. 